\title{
"Colossal" Interstitial Supersaturation in Delta Ferrite in Stainless Steels: (II) Low-temperature Nitridation of the 17-7 PH Alloy
}

\author{
D. Wang, H. Kahn, F. Ernst, and A.H. Heuer \\ Department of Materials Science and Engineering, \\ Case Western Reserve University \\ 10900 Euclid Avenue, Cleveland, OH, USA, 44106
}

\begin{abstract}
Low-temperature gas-phase nitridation has been studied in interstitially-hardened 17-7 precipitationhardening stainless steel. After nitridation, conventional transmission electron microscopy reveals that delta ferrite grains in such alloys show a uniform weak diffraction contrast. Chemical analysis reveals that the weak-contrast ferrite grains contain an enormous interstitial nitrogen supersaturation (> 20 at.\%). Surprisingly, there is no significant tetragonality in these weak-contrast ferrite grains. Such weak diffraction contrast is attributed to a nanometer-scale nitridation-induced spinodal decomposition of delta ferrite grains. In addition, nitride nanoparticles are observed in the steel, and were identified as rocksaltstructured $\mathrm{MN}$ nitride (M: Fe, Cr, Ni, and Al). Further, platelets of hexagonal $\mathrm{M}_{2} \mathrm{~N}_{1-x}$ are observed at low nitriding temperatures (623 and $653 \mathrm{~K})$, but are absent during nitridation at a higher temperature $(713 \mathrm{~K})$.
\end{abstract}

Keyword: Stainless steel, nitridation, ferrite, transmission electron microscopy. 


\section{Introduction}

In Part I of this work [1], we reported the presence of a "colossal" supersaturation of carbon interstitials (as high as 18 at.\%) in delta ferrite grains in 17-7 PH and 2205 duplex stainless steels following lowtemperature gas-phase carburization. The fully carburized grains near the surface showed an unusual weak, "featureless" diffraction contrast in conventional transmission electron microscopy (TEM), and electron diffraction revealed essentially no evidence of tetragonality or carbide formation. Carburization apparently occurs by nucleation and growth of weak-contrast high-carbon ferrite plates, as could be ascertained by the presence of partially carburized grains deeper into the hardened case.

A carbon-induced spinodal decomposition of delta ferrite to nanometer-scale Cr-rich and Fe-rich alpha ferrite phases was observed in the weak-contrast regions in high-resolution scanning TEM (STEM) [1]. In addition, an extremely high dislocation density was observed in the decomposed regions, which is consistent with the hypothesis that carbon segregation to dislocation cores effectively delays carbide precipitation and makes possible the "colossal" carbon supersaturation.

Similar to low-temperature carburization, interstitial hardening by low-temperature nitridation has been previously studied [2-8]. However, most studies focused on the austenite in these alloys [2, 3, 6-8]. The purpose of the present paper is to report the response of delta ferrite in the 17-7 alloy to low-temperature gas-phase nitridation. When the nitridation temperature was $713 \mathrm{~K}$, featureless ferrite was observed, whereas platelets of a nitride phase were observed when the alloy was treated at $623 \mathrm{~K}$ or $653 \mathrm{~K}$. The response of delta ferrite in the 2205 alloy to nitridation is quite different from that in the 17-7 alloy, and will be described in part Ш. 


\section{Experimental Procedure}

The same 17-7 PH stainless steel (condition A) was used in this study as in part I [1], which has a nominal composition of 17-19 at.\% $\mathrm{Cr}, 6.5-7.1$ at.\% Ni, 2 at.\% $\mathrm{Al}, \leq 1.0$ at.\% $\mathrm{Mn}, \leq 2.0$ at.\% Si, $\leq 0.4$ at.\% $\mathrm{C}$ and balance Fe. This steel contains 80 vol.\% austenite, 10 vol.\% martensite, and 10 vol.\% delta ferrite. Gas-phase double-activation low-temperature nitridation was carried out using $\mathrm{HCl}$ gas in situ in the activation step to remove the spontaneously formed $\mathrm{Cr}_{2} \mathrm{O}_{3}$-rich passivating surface oxide film, with $\mathrm{NH}_{3}$ gas as the source of active nitrogen during the actual nitridation step. The time-temperature nitridation "recipe" was similar to that used in ref. [2], except that the activation was performed at $598 \mathrm{~K}$ for $4 \mathrm{~h}$ and nitriding temperatures were 623,653 , or $713 \mathrm{~K}$; the second nitriding duration was $16 \mathrm{~h}$, corresponding to a total nitridation time of $20 \mathrm{~h}$. Nitriding was performed at nitriding activities of either 3000 or 7400 , as defined in ref. [2].

The microstructures of the nitrided samples were analyzed by TEM, using a Zeiss Libra 200EF (200 kV) and a FEI Tecnai F30 (300 kV). The specimen foils were prepared by focused ion beam (FIB) milling in two different scanning electron-/focused-ion beam instruments, a FEI Helios Nanolab 650 and a FEI Nova Nanolab 200. The specimen foils were prepared at $30 \mathrm{kV}$ and finally cleaned at $5 \mathrm{kV}$. Transmission Kikuchi diffraction (TKD) $[9,10]$ was performed on TEM foils in the FEI Nova Nanolab 200 equipped with an Oxford Nordlys high-resolution electron backscattered diffraction (EBSD) system to identify the phase(s) in the microstructure. Strain in the microstructure was analyzed by a Topspin system from NanoMEGAS $[11,12]$, attached to the Tecnai F30 TEM.

Microanalysis was performed on cross-sectioned samples using a PHI 680 scanning Auger electron microprobe (SAM), supplemented by atom probe tomography (APT) performed on a Cameca LEAP 4000X HR instrument. Atom-probe samples from a finely-polished cross section of nitrided 17-7 PH 
stainless steel were prepared by the FIB technique using the FEI Helios Nanolab 650. APT data was acquired in a laser mode with $20 \mathrm{pJ}$ laser power at a temperature of $50 \mathrm{~K}$. Due to peak overlap of ${ }^{14} \mathrm{~N}$ and

${ }^{28} \mathrm{Si}$, the peaks at all nitrogen positions were initially assigned to nitrogen in the spectrum of mass-tocharge ratio. The actual Si concentration was calculated based on the known natural abundances of its isotopes $\left({ }^{29} \mathrm{Si}\right.$ and $\left.{ }^{30} \mathrm{Si}\right)$ and subtracted from measured nitrogen concentration. Ion nitride species of $\mathrm{CrN}$, $\mathrm{AlN}$, and $\mathrm{CrN}_{2}$ generated during laser evaporation and were dully treated in the quantification of the dataset.

\section{Results}

\subsection{Morphology of nitrided delta ferrite grains}

Ferrite grains showing uniform weak contrast can be observed after nitridation at $713 \mathrm{~K}$ with a nitriding activity of 7400, as shown in Fig. 1a. In the cross section of the nitrided sample, two ferrite grains marked 1 and 2 close to the free surface (which is on the right) show weak contrast. The ferrite grain that is deeper in the case (arrowed and marked 3 in Fig. 1a) shows weak contrast in its top half, but regular diffraction contrast in its bottom half. This illustrates that during the low-temperature nitridation, ferrite grains can transform into a "phase" showing weak contrast directly, without the transitional, platecontaining morphology we observed in the case of low-temperature carburization of the same alloy [1].

Platelets were observed in the nitrided ferrite grains in 17-7 PH stainless steel, but only after nitridation at lower temperatures $(623$ or $653 \mathrm{~K})$. As shown in Fig. 1b, there are two sets of platelets, one more dominant than the other. The platelets in each set are parallel to each other. The two sets of the plates form pairs and each pair appear to have nucleated from the same interface (an austenite-ferrite phase boundary), and intersected at a fixed angle, suggesting they are most likely orientational variants of the same nitrogen-containing phase. A long plate is observed lying horizontally across the ferrite grain, with 
the absence of its orientational variant; this feature may be pre-existing in the ferrite grain before nitridation.

\subsection{Composition of nitrided delta ferrite grains}

A nitrogen concentration-depth profile in a ferrite grain was obtained from a SAM line scan from the sample of Fig. 1a, and indicates a case depth of $13 \mu \mathrm{m}$ (Fig. 2). The surface nitrogen concentration is about 19 at.\% and the nitrogen concentrations measured in the nitrided delta ferrite grains (identified by their high $\mathrm{Cr}$ and low Ni contents) are of the same magnitude, at least two orders of magnitude higher than the equilibrium solubility in ferrite at the nitriding temperature [13].

A three-dimensional (3D) APT nitrogen atom map from a weak-contrast nitrided ferrite grain (near the free surface) is shown in Fig. 3a. (The bottom of the original dataset was cut off after data reconstruction due to the unexpected presence of a $\mathrm{NbC}$ particle.) The nitrogen concentration measured in this ferrite grain is 14 at.\%. However, this is lower than the nitrogen concentration measured by SAM. The discrepancy can possibly be explained by the same APT analytical artifact as occurs for carbon analysis in steels [14], and has been discussed in Part I [1].

The nitrogen distribution in the ferrite is uniform, similar to that of carbon-supersaturated carburized ferrite in this steel [1]. A proximity diagram of 18 at.\% nitrogen was computed and is shown in Fig. 3b. The concentration profiles of $\mathrm{Fe}, \mathrm{Cr}, \mathrm{Ni}$, and $\mathrm{Al}$ across the isoconcentration interfaces are normalized without nitrogen and clearly show that the nitrogen-rich clusters $(\approx 2 \mathrm{~nm}$ in diameter) are enriched in $\mathrm{Cr}$ and $\mathrm{Al}$, but depleted in Fe. The size of the clusters is consistent with the features observed in the TEM to be shown later. Further, the proximity diagram shows that the maximum nitrogen concentration in the nitrogen-rich clusters is at least 25 at. $\%$. 
$\mathrm{NiAl}$ precipitates that form due to the nitridation heat treatment in ferrite grains have been discussed in a separate publication [15]. NiAl clusters cannot be identified by cluster analysis, suggesting that NiAl clusters that could have formed due to the nitridation heat treatment (see Figs. 4 and 5 below) apparently dissolved or never formed during nitridation.

APT data was also acquired from a plate-containing ferrite grain nitrided at $653 \mathrm{~K}$ with a nitriding activity of 3000 (the sample of Fig. 1b). The nitrogen distribution in the grain was also uniform (data not shown here), but the nitrogen concentration in the volume is lower, 10.3 at.\%. The lower nitrogen concentration can be attributed to both the lower nitriding temperature and lower nitrogen activity, as well as the depth of the delta ferrite grain in the nitrided alloy. In the analyzed volume, similar Cr- and N-rich nanometerscale clusters were observed. However, there was no evidence of platelet-shaped features in the volume, indicating that (unfortunately) the platelets were not captured in this particular sample.

\subsection{Structure of delta ferrite grains}

A diffraction pattern acquired from a ferrite nitrided at $713 \mathrm{~K}$ along a $\langle 011\rangle_{\text {BCC }}$ zone axis is shown in Fig. 4. There are diffuse streaks along a $[001]_{\mathrm{BCC}}$ direction towards smaller reciprocal lattice spacings, similar to those of carburized ferrite in this steel [1]. Streaking along a $[001]_{\mathrm{BCC}}$ direction has also been observed in ion-nitrided ferritic and martensitic stainless steels [16], which was attributed to the formation of small coherent nitrides.

In addition, there is an additional set of reflections in the $\langle 011\rangle_{\text {BCC }}$ pattern, which indicates a second phase possessing a cubic (rocksalt) structure, $\mathrm{MN}$ (with $\mathrm{M}$ being a combination of $\mathrm{Fe}, \mathrm{Cr}, \mathrm{Ni}$, and $\mathrm{Al}$ ), 
and forming the Bain orientation relationship (OR) with the matrix, as previously observed in nitrided 17$4 \mathrm{PH}$ and 17-7 PH stainless steels [5-8].

Dark-field (DF) images acquired from such grains indicate that the nitride particles forming within the grain are extremely small, in the range 1 to $2 \mathrm{~nm}$ [8]. This is in good agreement with the APT data (Fig. 3b) showing that small $\mathrm{N}-, \mathrm{Cr}-$, and $\mathrm{Al}-$-rich clusters are present. In addition, the strain fields from such a high density of coherent precipiates could dominate the TEM contrast [17].

Diffraction patterns along other BCC zone axes were also acquired from weak-contrast ferrite grains (not shown here) [8], which confirms the Bain OR between the ferrite matrix and the nitride nanoprecipitates.

As shown in Part I [1], low-temperature carburization apparently causes ferrite grains to spinodally decompose into (Cr, C-rich) and (Fe, C-poor) nanoscale regions. A similar microstructure forms in the nitrided weak-contrast ferrite grain in this study. A high-resolution (HR) TEM image from a weakcontrast ferrite grain orientated to a $\langle 111\rangle_{\mathrm{BCC}}$ viewing direction is shown in Fig. 5a, revealing that the weak-contrast grain contains bright islands separated by surrounding dark highly disturbed regions, similar to the observations from low-temperature carburized ferrite grains [1]. The size of such regions is in good agreement with the proximity diagram shown in Fig. $3 b$.

Figure 5b, a magnified region of Fig. 5a, shows 3 sets of $\{220\}$ lattice fringes producing the three-fold symmetry expected for the <111> viewing direction. However, the lattice image shows some highly disturbed regions, which are circled in Fig. 5, indicating a high density of structural defects. This agrees with previous observations in the carburized delta ferrite in Part I, i.e. the dislocation density is $\approx 10^{16} \mathrm{~m}^{-2}$. 
Although performing Burgers circuits yields closure failures in certain regions of the image, it may not be assumed that corresponding straight edge-character dislocation segments exist that penetrate the entire $\approx 30 \mathrm{~nm}$ thick TEM foil in the viewing direction. Actually, interpretation of Fig. $5 \mathrm{~b}$ in terms of projected atomistic structure is complicated by the fact that the spacing of the $\{220\}$ planes that make up the lattice image are beyond the point-resolution limit of the Tecnai F30 HREM. Accordingly, the image was recorded under conditions corresponding to possibly significant Fourier filtering, which may introduce severe imaging artifacts. Nevertheless, the lateral fluctuations of lattice contrast and average intensity on a length scale of about $1 \mathrm{~nm}$ indicate a very high density of crystal dislocations - particularly in directions inclined against the viewing direction. Further, plane bending and surface roughness may also introduce some lattice contrast, most likely introduced by dislocations and their impact on surface relaxation and ion-milling rates during specimen preparation.

Figure 6 shows diffraction patterns acquired from the partially nitrided (arrowed) ferrite grain shown in Fig. 1a. Both patterns show extra reflections due to $\mathrm{NiAl}$ precipitates (the weak reflections between strong BCC matrix reflections), as was previously observed in plate-containing ferrite after low-temperature carburization [1]. Comparing the two diffraction patterns recorded from the weak-contrast (top) and original (bottom) portions of the grain, in the absence of nitride reflections, all reflections (including ferrite matrix and $\mathrm{NiAl}$ reflections) are present. Except for the diffraction pattern acquired from the weakcontrast region (Fig. 6b), there are signs of diffuse streaks along [001 $]_{\mathrm{BCC}}$ directions towards smaller reciprocal spacings (reflections are elongated rather than circular), suggesting the weak-contrast appearance is related to a lattice distortion (local expansion) in the ferrite, and that nitride formation is not necessary for the weak-contrast appearance. This is in good agreement with diffraction patterns of the same zone axis acquired from plate-containing ferrite after carburization [1]. 
Strain analysis was performed on the same partially transformed delta ferrite grain arrowed in Fig. 1a and shown in Fig. 7a. Figure 7b is a virtual bright-field image [18] of the Fig. 7a; the grain in red is where the strain maps were acquired. Figure 7c shows the reference diffraction pattern used in the strain analysis. The reference diffraction pattern was acquired from the original ferrite region; the corresponding strain at the reference point is set to be 0 . The lines in Figs. $7 \mathrm{~b}$ and $7 \mathrm{c}$ indicate the directions of the strain analysis $-[001]_{\mathrm{BCC}}$ in the $x$ direction. Figures $7 \mathrm{~d}$ and $7 \mathrm{e}$ are the strain maps along the $x$ and $y$ directions with respect to the $[001]_{\mathrm{BCC}}$ direction. The map shows that the strains within the transforming ferrite grain can be as large as $2.5 \%$. Since this strain is much higher than the expected yield strain, plastic deformation would be expected within the grain. Further, the observed strain could explain the streak formation in Fig. $6 \mathrm{~b}$, i.e. local deformation was induced by the nitridation process. The compressive strain in the $y$ direction of the grain generally follows the diffusion direction of nitrogen in the sample. The strain map also suggests $\approx 1.5 \%$ deformation threshold for the weak-contrast transformation.

Figure 8 shows transimission Kikuchi diffraction data acquired from the same partially transformed delta ferrite grain (arrowed in Fig. 1). The Kikuchi pattern quality deteriorates from the bottom portion of the grain (Fig. 8b) to its top portion (Fig. 8c). The pattern acquired from the bottom portion of the grain (corresponding to the portion of the grain that still shows diffraction contrast and is relatively strain free) is sharp. Even though the whole pattern from the top portion (corresponding to the portion of the grain that shows weak contrast and under compressive strain) appears similar, many details in the pattern are missing, e.g. a few weak (high indexed) Kikuchi bands are no longer visible in Fig. 8c. The Kikuchi pattern from the highly-deformed ferrite grain on the right is shown in Fig. 8d. The Kikuchi bands in the pattern were completely smeared out. The Kikuchi pattern from an austenite grain (Fig. 8e) at a similar depth can still be easily resolved. This suggests that both high residual stresses and a high dislocation density introduced during low-temperature nitridation internally distort the ferrite grain. 
The diffraction patterns shown in Fig. 9 were acquired from a plate-containing ferrite grain after nitridation at $653 \mathrm{~K}$ with a nitriding activity of 3000 . The ferrite matrix was tilted to a $\langle 011\rangle_{\mathrm{BCC}}$ zone axis, as shown in Fig. 9a. Sharp extra reflections (circled in the inset of the Fig. 9b) from the plates were observed, indicating that plate formation in the ferrite grain is different from the carbide-free platecontaining carburized ferrite discussed in Part I, where no extra reflcetions were observed. A hexagonal nitride, $\mathrm{M}_{2} \mathrm{~N}$, was identified with lattice parameters $a=0.47 \mathrm{~nm}$ and $c=0.42 \mathrm{~nm}$. The $\mathrm{OR}$ of this nitride with the ferrite is given in Eqns. (1) and (2):

$$
\begin{gathered}
(112)_{\delta} / /(10 \overline{1} 0)_{\mathrm{M}_{2} \mathrm{~N}}, \\
<011>_{\delta} / /<0001>_{\mathrm{M}_{2} \mathrm{~N}} .
\end{gathered}
$$

This OR was previously observed in other high-Cr stainless steels $[19,20]$. Even though the $a$ lattice constant matches the $\mathrm{Cr}_{2} \mathrm{~N}$ standard structure [21], the $c$ lattice parameter is smaller, which is probably due to a nitrogen-deficient structure. A dark-field image from a nitride reflection clearly shows nitride plates in the ferrite grain (Fig. 9b). In addition to the extra reflections due to nitride formation, diffuse streaks along a $[001]_{\mathrm{BCC}}$ direction were again observed (Fig. 9a).

In the plate-containing ferrite grain (Fig. 1b), the plate-free region is accompanied by similar diffuse streaks along $[001]_{\mathrm{BCC}}$ in the diffraction pattern (Fig. 9c) and similar Cr- and N-rich clusters. Therefore, similar weak contrast is observed in the plate-free region of the plate-containing delta ferrite. In addition, discrete nitride reflections in the diffraction pattern are absent, indicating the absence of nitride in the plate-free region. 
Transimission Kikuchi diffraction data (Fig. 10) were acquired from the plate-containing delta ferrite grain shown in Fig. 1b. (The pixelated appearance in this image is due to the limits of spatial resolution for this technique reaching.) Due to the extreme lattice distortion, the nitrided ferrite could not be indexed. Nitride platelets, on the other hand, could be indexed, a trigonal nitride, $\mathrm{M}_{2} \mathrm{~N}$ (space group $\mathrm{P} \overline{3} 1 \mathrm{~m}$ ) [21] being identified. A typical pattern from such a platelet shows well-defined bands (Fig. 10c), although the matching between the experimental pattern and simulation is not perfect. Several bands in Fig. 10d were misaligned with the simulation, suggesting a deviation of the nitride structure from the standard structure.

\section{Discussion}

\subsection{Nitrided weak-contrast ferrite}

All nitrided weak-contrast delta ferrite grains possess significant nitrogen concentrations $(\approx 20$ at. $\%)$. The nitrogen concentration in a ferrite grain at a depth of $9 \mu \mathrm{m}$ revealed by the SAM line scan is $\approx 20$ at. $\%$ (Fig. 2b). Similar to carburized ferrite grains, nitrided ferrite grains with a significant nitrogen concentration show negligible tetragonality (distinct reflections would be expected from a tetragonal structure), but a significant lattice distortion along a $[001]_{\mathrm{BCC}}$ direction (the lattice distortion is not uniform within the grain). According to the APT results, clusters enriched in nitrogen forming in the weak-contrast ferrite grain are enriched in $\mathrm{Cr}$ and $\mathrm{Al}$. Such a large nitrogen concentration and the uniform distribution in the ferrite grain suggest a similar weak-contrast ferrite formation mechanism as was proposed in Part I for weak-contrast carburized delta ferrite grains, i.e. nitrogen segregation to dislocation cores and nitrogen-induced spinodal decomposition. The enormous dislocation density leads to overlap of strain fields of the closely-spaced dislocations, leading to the weak contrast under conventional TEM imaging (as well as smearing out of Kikuchi pattern). In other words, all the factors that contribute to the weak-contrast in carburized ferrite in this alloy are present in nitrided ferrite. 
However, the underlying dislocation mechanism does not prevent nitride formation, and nitride formation is not necessary for weak-contrast ferrite. If two competitive mechanisms are considered for the weakcontrast delta ferrite formation during low-temperature nitridation, i.e. nitrogen segregation to dislocation cores and nitride formation, it appears that the former occurs to form nitrogen-supersaturated ferrite, prior to the formation of any nitride. This interpretation is supported by the formation of non-stoichiometric nitrides, as well as the diffraction data in Fig. 6, which show that diffuse streaks along a $[001]_{\mathrm{BCC}}$ direction appear before any sign of nitride reflections. In particular, if nitrides form first, nitrogen dissolution should reach the stoichiometric $\mathrm{M} / \mathrm{N}$ ratio before nitrogen segregates to dislocation cores, or could even cause transformation of a ferrite grain into a nitride. In addition, uniformly distributed small nitride particles suggest that the postulated massive dislocation network served as nitride nucleation sites after nitrogen supersaturation. Nitrogen saturation in the ferrite matrix may result from saturation of the dislocation density in the ferrite [22], which is limited by the elastic interactions between dislocations. Lastly, chromium nitride in austenitic steel was reported to be unstable and to dissolve in a heavily deformed environment $[23,24]$, which is similar to previously reported cementite decomposition under severe plastic strain in pearlitic steels $[25,26]$.

The small and uniformly-distributed rocksalt-structured MN nitride precipitates that were observed in nitrided ferrite grains have a lattice parameter of $0.408 \mathrm{~nm}$ [8]. This could probably be ascribed to a nitrogen-deficient nitride $\left(\mathrm{MN}_{1-x}\right)$, as the lattice parameter of stoichiometric $\mathrm{CrN}$ is $0.415 \mathrm{~nm}$. Though $\mathrm{CrN}$ is often assumed to be stoichiometric, under non-equilibrium conditions [27-29], the lattice parameter of $\mathrm{CrN}_{1-\mathrm{x}}$ depends on the $\mathrm{Cr} / \mathrm{N}$ ratio, i. e. nitrogen deficiency in the lattice gives a smaller $\mathrm{CrN}_{1}$ ${ }_{x}$ lattice parameter. A similar nitrogen-deficient nitride $\left(\mathrm{MN}_{1-x}\right)$ was observed by APT in the cellular nitride formed at the austenite-ferrite phase boundaries after low-temperature nitridation [8]. 
Even though formation of rocksalt-structured nitride is not the nitride expected according to the phase diagram and CALPHAD calculations, precipitation of coherent rocksalt-structured nitride can be kinetically favored. It has been shown that $\mathrm{Fe}-\mathrm{Al}$ alloys, which usually precipitate incoherent hexagonal AlN nitride, favor precipitation of metastable coherent roacksalt-structured AlN in the presence of a high dislocation density [26]. Once the nitridation-induced dislocations are saturated by nitrogen, these dislocations can serve as heterogeneous nucleation sites for nitride precipitates to accommodate the additional nitrogen present in the ferrite. Because the dislocations are uniformly-distributed in the ferrite, a corresponding uniformly-distributed nitride could be expected. Even though the nucleation barrier of the $\mathrm{MN}_{1-x}$ nitride can be effectively eliminated by the presence of dislocations [30, 31], nitride growth is limited by the sluggish diffusion of substitutional solutes at the nitriding temperatures.

\subsection{Nitrided plate-containing ferrite}

Plate-containing ferrite grains were observed only after nitridation at temperatures of $653 \mathrm{~K}$ or below, regardless of nitriding activities. The platelets were identified as hexagonal $\mathrm{M}_{2} \mathrm{~N}$ nitride. The plate-free regions in the ferrite grains show weak contrast, and diffuse streaks were observed along $[001]_{\mathrm{BCC}}$ directions in diffraction patterns.

Nitridation in austenitic stainless steels at lower temperatures generally produces a relatively low (but still "colossal") nitrogen concentration at the alloy surface [2], which reduces the magnitude of residual compressive stresses $[2,32]$. The formation of weak-contrast ferrite is the result of a competition between dislocation formation and nitride formation. A lower nitrogen concentration in the hardened case decreases the magnitude of the residual stresses, and therefore nitride formation may dominate the response of the ferrite grain before significant dislocation generation occurs. 
However, other important factors must also be considered for nitridation at lower temperatures, i.e. the exothermic nature of nitrogen dissolution in ferrite and the much lower nitrogen diffusivity. Dissolution of nitrogen in ferrite is endothermic, but a critical concentration of $\mathrm{Cr}$ in the ferrite changes nitrogen dissolution from an endothermic to an exothermic process [13]. Lower nitridation temperatures thus would favor higher nitrogen solubilities in the ferrite, and would thermodynamically delay nitride formation. Moreover, the nitrogen diffusivity at $713 \mathrm{~K}$ is higher than that at $653 \mathrm{~K}$ by a factor of $\approx 16$ (estimated based on case depths after nitridation, 13 and $3 \mu \mathrm{m}$, respectively). Therefore, during nitridation at $713 \mathrm{~K}$, the stress level of the ferrite changes from zero to several GPa within $3 \mathrm{~h}$ (roughly estimated based on a $20 \mathrm{~h}$ nitridation duration and a ferrite grain size of $2 \mu \mathrm{m}$ ). However, for nitridation at $653 \mathrm{~K}$, it would take up to $13 \mathrm{~h}$ to build up a similar stress (strain) level around the same ferrite grain. Therefore, kinetically, nitrides have a much larger window to nucleate and grow before a critical stress (strain) level is achieved at low temperatures. Even though nitride formation is favored at high temperatures, due to the residual stresses, nitride formation is inhibited as a result of a competition between dislocation generation and nitride formation. On the other hand, at low temperatures, a higher nitrogen content in the ferrite and a longer nitride formation window enable nitride nucleation and growth prior to significant dislocation generation.

After $\mathrm{M}_{2} \mathrm{~N}_{1-x}$ nitride formation occurs in the delta ferrite grain, a transition from the original ferrite to weak-contrast ferrite occurred in nitride-free regions. When nitrogen is introduced into the ferrite at low temperatures, nitride plate formation is preferred. As the stresses (strain) continue increasing in the hardened case, once past the critical level, dislocations are generated and the nitride-free portions of ferrite begin to decompose spinodally [1] and eventually show weak contrast. Due to the previously formed 
$\mathrm{M}_{2} \mathrm{~N}_{1-x}$ nitride, nitrogen in the nitride-free regions cannot saturate the ferrite and $\mathrm{MN}$ nitride was not observed.

\subsection{Comparison of carburized and nitrided weak-contrast delta ferrite}

A much higher interstitial concentration in ferrite was observed after nitridation than after carburization, especially in deeper regions of the case. The nitrogen concentration is about 20 at. $\%$ in a ferrite grain $\approx 9$ $\mu \mathrm{m}$ away from the free surface, while ferrite after carburization at a similar depth contains less than 5 at. $\%$ carbon. This can be attributed to a flat nitrogen concentration-depth profile after nitridation*. In the carburized stainless steel, the carbon concentration achieved at the free surface was up to 15 at.\% [35], which is lower than the nitrogen concentration obtained after nitridation $(\approx 20$ at.\%). Therefore, the chemical potential gradient driving nitrogen into ferrite is correspondingly higher than that of carbon (assuming the chemical potentials of carbon and nitrogen are proportionally related with their concentrations, respectively, and they encounter the same $\mathrm{Cr}$ concentration in austenite grains), which makes nitrogen saturation of dislocation cores possible, thereby leading to subsequent nitride formation. The absence of carbides in the carburized ferrite is probably due to the carbon concentration in the ferrite being unable to reach the threshold value to saturate all dislocations that may be present, and is actually limited by the carbon concentration in the neighboring austenite grains. More importantly, compared to the formation energy of nitride, carbides are much less stable than nitrides of the same elements, suggesting carbide formation can be inhibited more easily [36].

Another interesting difference between ferrite grains after carburization and nitridation is that during nitridation, ferrite grains transform to the weak-contrast appearance directly, while a transient stage involving high carbon plate formation was observed after carburization. The absence of transition plates in nitrided weak-contrast ferrite grains could be due to the higher nitrogen concentration. 
Assuming for the moment that the concentration-depth profile is due to a highly concentration-dependent diffusion for both carbon and nitrogen diffusion in austenitic stainless steels, they are comprised of two parts: a plateau and a sharp tail. The transition from tail to plateau could happen within a distance of 1 2 $\mu \mathrm{m}$. The maximum compressive residual stresses induced by interstitial carbon is $\approx 3 \mathrm{GPa}$ [35]. However,

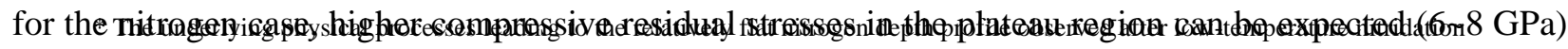
are still very much under discussion. There are two hypotheses, i.e. a strong concentration dependence of the nitrogen diffusivity

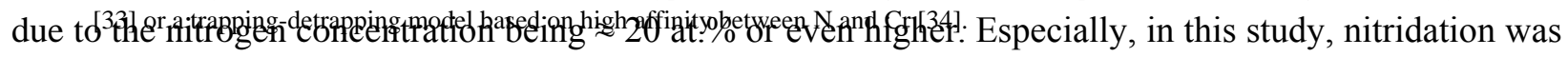
carried out at a higher temperature $(713 \mathrm{~K})$ compared to that of the carburization in Part I $(653 \mathrm{~K})$, and nitrogen has a higher diffusivity by a factor of 4 . Consequently, the material during nitridation compared to that during carburization experiences a more abrupt change from a stress-free state (or one with negligible residual stresses) at the diffusion front to a highly-stressed state in the plateau region.

Therefore, as the nitrogen diffuses to a ferrite grain, which has dimension of approximately 1-2 $\mu \mathrm{m} \times 1-2$ $\mu \mathrm{m}$, the compressive stresses applied on it by its neighboring austenite grains changes from zero to several GPa within a distance of $1 \sim 2 \mu \mathrm{m}$. This could happen within a single ferrite grain, as in the transforming ferrite grain observed in Figs. 1a and 7. The strain difference within the ferrite grain is estimated at $2.5 \%$, which corresponds to several GPa. Under such high stresses, dislocation systems in a ferrite grain at the nitrogen diffusion front are likely activated simultaneously and uniformly, compared to the situation that occurs within a hardened case during carburization, where the several dislocation systems are activated discretely and sequentially in a gradually varying stress field (carburization takes longer time and achieves lower compressive stresses compared to those achieved during nitridation).

\section{Conclusion}


Delta ferrite grains in 17-7 precipitation-hardening stainless steel show a uniform weak contrast in TEM images after low-temperature $(713 \mathrm{~K})$ nitridation. Even though similar weak contrast ferrite was observed after carburization, the effect of nitridation differs in several important ways from that of carburization. A much higher nitrogen concentration can be achieved after nitridation, which correspondingly induces much higher compressive residual stresses in the hardened case. Such high residual stresses apparently induced nitrided ferrite grains to transform to weak-contrast appearance directly without any transition stage. Higher nitrogen concentration and the higher thermal stability of nitrides (compared to carbides) give rise to rocksalt-structured nitride formation in the weak-contrast ferrite. Plate-containing ferrite grains were only observed in samples nitrided at lower temperatures (623 K and $653 \mathrm{~K}$ ), and the plates were identified as hexagonal $\mathrm{M}_{2} \mathrm{~N}_{1-x}$ nitride. This can be attributed, at least in part, to the exothermic nature of nitrogen dissolution in ferrite compared with endothermic carbon dissolution in the same phase.

\section{Acknowledgement}

We acknowledge the NSF for financial support, grant No. DMR-1104937, and AK Steel for providing 17-7 PH stainless steel samples, and the Swagelok Center for Surface Analysis of Materials (SCSAM) at Case Western Reserve University and the Electron Microbeam Analysis Laboratory (EMAL) at University of Michigan for access to the characterization facilities, and A. H. Hunter and E. Marquis for their assistance.

\section{Reference}

[1] D. Wang, C.-W. Chen, H. Kahn, G.M. Michal, F. Ernst, A.H. Heuer, "Colossal” interstitial supersaturation in delta ferrite in stainless steels-I. Low-temperature carburization, Acta Mater. 86 (2015) 193-207.

[2] D. Wu, H. Kahn, J.C. Dalton, G.M. Michal, F. Ernst, A.H. Heuer, Orientation dependence of nitrogen supersaturation in austenitic stainless steel during low-temperature gas-phase nitriding, Acta Mater. 79 (2014) 339-350.

[3] T. Christiansen and M. A. J. Somers, Controlled dissolution of colossal quantities of nitrogen in stainless steel, Metall. Mater. Trans. A 37A (2006) 675-682. 
[4] H. Dong, S-Phase Surface Engineering of $\mathrm{Fe}-\mathrm{Cr}, \mathrm{Co}-\mathrm{Cr}$ and Ni-Cr Alloys, Int. Mater. Rev. 55(2010) 65-98

[5] H. Dong, M. Esfandiari, X.Y. Li, On the microstructure and phase identification of plasma nitrided 17-4PH precipitation hardening stainless steel, Surf. Coat. Technol. 202 (2008) 29692975.

[6] Y. Sun, T. Bell, Low Temperature Plasma Nitriding Characteristics of Precipitation Hardening Stainless Steel, Surf. Eng. 19 (2003) 331-336.

[7] P. Kochmanski, J. Nowacki, Activated gas nitriding of 17-4 PH stainless steel, Surf. Coat. Technol. 200 (2006) 6558-6562.

[8] D. Wang, F. Ernst, H. Kahn, A.H. Heuer, Cellular Precipitation at a 17-7 PH Stainless Steel Interphase Interface During Low-Temperature Nitridation, Metal. Mater. Trans. A 45 (2014) 3578-3585.

[9] R.R. Keller, R.H. Geiss, Transmission EBSD from $10 \mathrm{~nm}$ domains in a scanning electron microscope, J. Microsc. 245 (2012) 245-251.

[10] P.W. Trimby, Orientation mapping of nanostructured materials using transmission Kikuchi diffraction in the scanning electron microscope, Ultramicrosc. 120 (2012) 16-24.

[11] A.D. Darbal, R.D. Narayan, C. Vartuli, T. Aoki, J. Mardinly, S. Nicolopoulos, J.K. Weiss, Applications of automated high resolution strain mapping in TEM on the study of strain distribution in MOSFETs, Microsc. Microanal. 20 (2014) 1066-1067.

[12] M.P. Vigouroux, V. Delaye, N. Bernier, R. Cipro, D. Lafond, G. Audoit, T. Baron, J.L. Rouvière, M. Martin, B. Chenevier, F. Bertin, Strain mapping at the nanoscale using precession electron diffraction in transmission electron microscope with off axis camera, Appl. Phys. Lett. 105 (2014) 191906.

[13] J.C. Dalton, Masters Thesis, Case Western Reserve University, 2014.

[14] M. Thuvander, J. Weidow, J. Angseryd, J.K.L. Falk, F. Liu, M. Sonestedt, KStiller, H.-O. Andren, Quantitative atom probe analysis of carbides, Ultramicrosc. 111 (2011) 604-608.

[15] D. Wang, H. Kahn, F. Ernst, A.H. Heuer, NiAl precipitation in delta ferrite grains of 17-7 precipitation-hardening stainless steel during low-temperature interstitial hardening, Scripta Mater. 108 (2015) 136-140.

[16] K. Ozbaysal, O.T. Inal, Structure and properties of ion-nitrided stainless steels, J. Mater. Sci., 21 (1986) 4318-4326.

[17] J.H. Driver, J.M. Papazian, The electron and field ion metallography of zones in nitrided FeMo alloys, Acta Metall. 21 (1973) 1139-1149.

[18] J. Portillo, E.F. Rauch, S. Nicolopoulos, M. Gemmi, D. Bultreys, Precession Electron Diffraction Assisted Orientation Mapping in the Transmission Electron Microscope, Mater. Sci. Forum 644 (2010) 1-7.

[19] J.O. Nilsson, A. Wilson, Influence of isothermal phase transformations on toughness and pitting corrosion of super duplex stainless steel SAF 2507, Mater. Sci. Technol. 9 (1993) 545554.

[20] K.A. Bywater, D.J. Dyson, The Precipitation of Cr2N in 17\%Cr Steels, Met. Sci. 9 (1975) 155-162.

[21] S.J. Kim, T. Marquart, H.F. Franzen, Structure refinement for $\mathrm{Cr}_{2}$ N, J. Less-Common Met., 158 (1990) L9-L10.

[22] S. Takaki, T. Tsuchiyama, K. Nakashima, H. Hidaka, K. Kawasaki, Y. Futamura, Microstructure development of steel during severe plastic deformation, Met. Mater. Int., 10 (2004) 533-539. 
[23] V.A. Shabashov, L.G. Korshunov, V.V. Sagaradze, N.V. Kataeva, A. E. Zamatovskii, A.V. Litvinov, K.A. Lyashkov, Nitrogen distribution in austenitic high-nitrogen chromium-manganese steel under friction and high-pressure torsion, Phys. Met. Metall. 114 (2013) 681-691.

[24] V.V. Sagaradze, Diffusion transformations in steels due to cold deformation, Metal. Sci. Heat Treat. 50 (2008) 422-429.

[25] Y. Ivanisenko, W. Lojkowski, R.Z. Valiev, H.J. Fecht, The mechanism of formation of nanostructure and dissolution of cementite in a pearlitic steel during high pressure torsion, Acta Mater. 51 (2003) 5555-5570.

[26] Y.J. Li, P. Choi, C. Borchers, S. Westerkamp, S. Goto, D. Raabe, R. Kirchheim, Atomicscale mechanisms of deformation-induced cementite decomposition in pearlite, Acta Mater. 59 (2011) 3965-3977.

[27] Y. Tsuchiya, K. Kosuge, Y. Ikeda, T. Shigematsu, S. Yamaguchi, N. Nakayama, Nonstoichiometry and antiferromagnetic phase transition of NaCl-type $\mathrm{CrN}$ thin films prepared by reactive sputtering, Mater. Trans. JIM, 37 (1996) 121-129.

[28] F. Huang, G. Wei, J.A. Barnard, M.L. Weaver, Microstructure and stress development in magnetron sputtered TiAlCr(N) films, Surf. Coat. Technol., 146-147 (2001) 391-397.

[29] M. Chen, S. Wang, J. Zhang, D. He, Y. Zhao, Synthesis of Stoichiometric and Bulk CrN through a Solid-State Ion-Exchange Reaction, Chem. Eur. J. 18 (2012) 15459-15463.

[30] M.H. Biglari, C.M. Brakman, E.J. Mittemeijer, Crystal structure and morphology of AIN precipitating on nitriding of an Fe-2at.\% Al alloy, Phil. Mag. A, 1995, 72, 1281-1299.

[31] M.H. Biglari, C.M. Brakman, E.J. Mittemeijer, S. Van der Zwaag, The kinetics of the internal nitriding of Fe-2 at. pct Al alloy, Metall. Mater. Trans. A, 26 (1995) 765-776.

[32] T.L. Christiansen, T.S. Hummelshoj, M.A.J. Somers, Expanded austenite, crystallography and residual stress, Surf. Eng., 26 (2010) 242-247.

[33] X. Gu, G.M. Michal, F. Ernst, A.H. Heuer, Numerical Simulations of Carbon and Nitrogen Composition-Depth Profiles in Nitrocarburized Austenitic Stainless Steels, Metall. Mater. Trans. A, 45 (2014) 4268-4279.

[34] S. Parascandola, W. Moller, D.L. Williamson, The nitrogen transport in austenitic stainless steel at moderate temperatures, App. Phys. Lett. 76 (2000) 2194-2196.

[35] H. Kahn, G.M. Michal, F. Ernst, A.H. Heuer, Poisson Effects on X-Ray Diffraction Patterns in Low-Temperature-Carburized Austenitic Stainless Steel, Metall. Mater. Trans. A 40A (2009) 1799-1804.

[36] H.L. Schick, Thermodynamics of certain refractory compounds, Academic Press, 1966. 

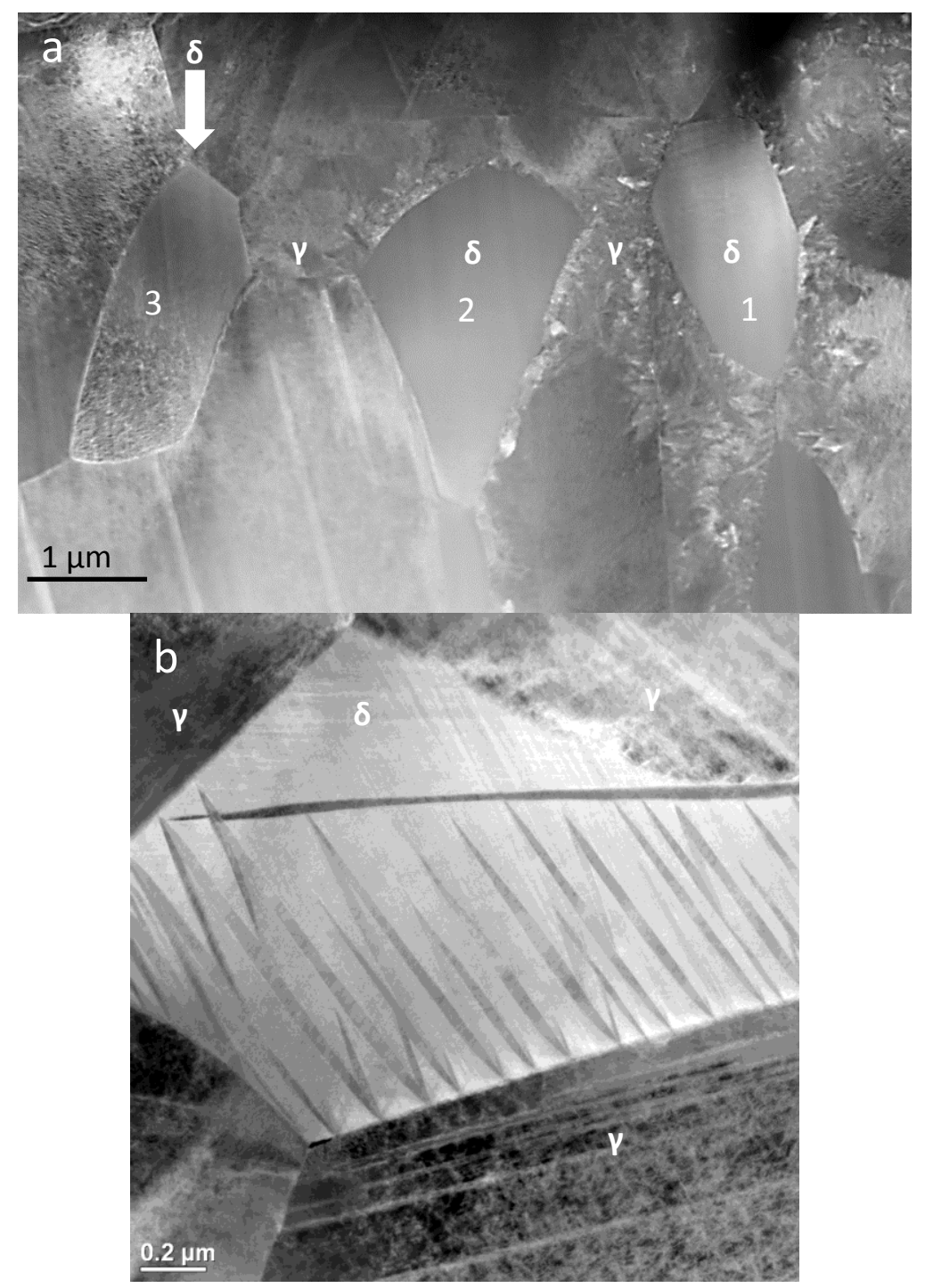

Fig. 1 STEM images of cross sections of nitrided 17-7 PH stainless steel. (a) The original alloy surface is $\approx 6 \mu \mathrm{m}$ to the right (nitridation at $713 \mathrm{~K}$, nitrogen activity of 7400). Grains 1 and 2 show the weak contrast, while only the top half of grain 3 shows this contrast. (b) Ferrite grain with platelets after nitridation at $653 \mathrm{~K}$ with a nitriding activity of 3000 . 


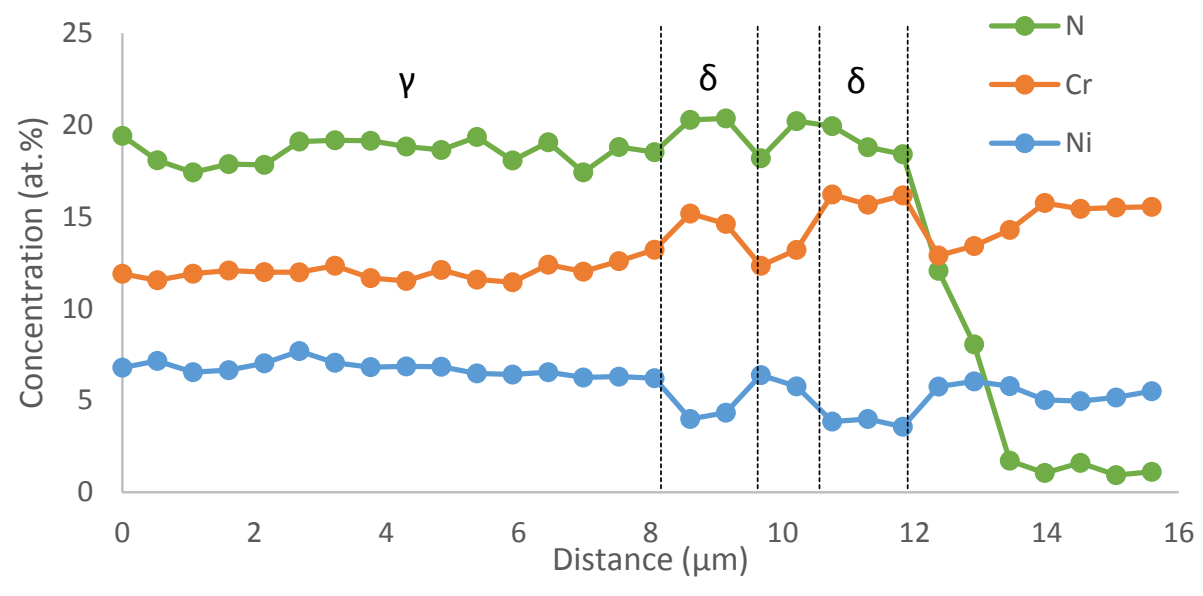

Fig. 2 Elemental profiles deduced from a SAM line scan on the sample of Fig. 1a. The dashed lines indicate the approximate delta ferrite-austenite phase boundaries. The original surface of the sample is at $0 \mathrm{~nm}$ and the nitrogen concentration is close to the as-received value at $13 \mu \mathrm{m}$. 
a

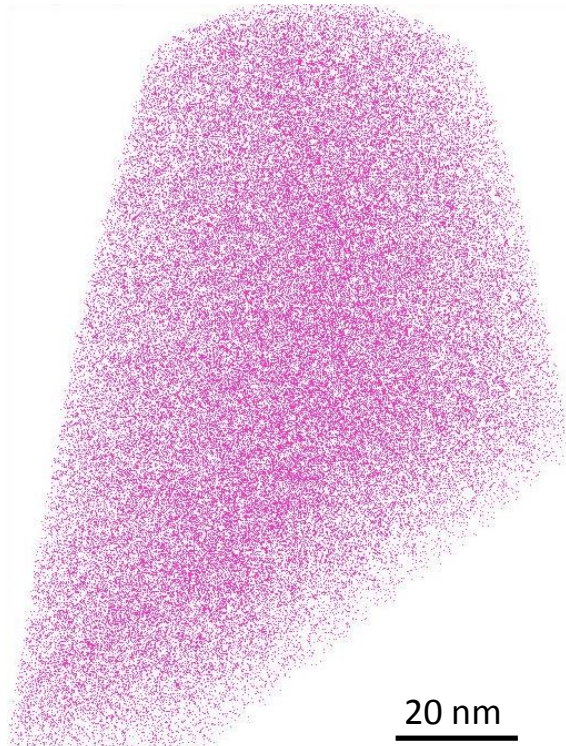

b

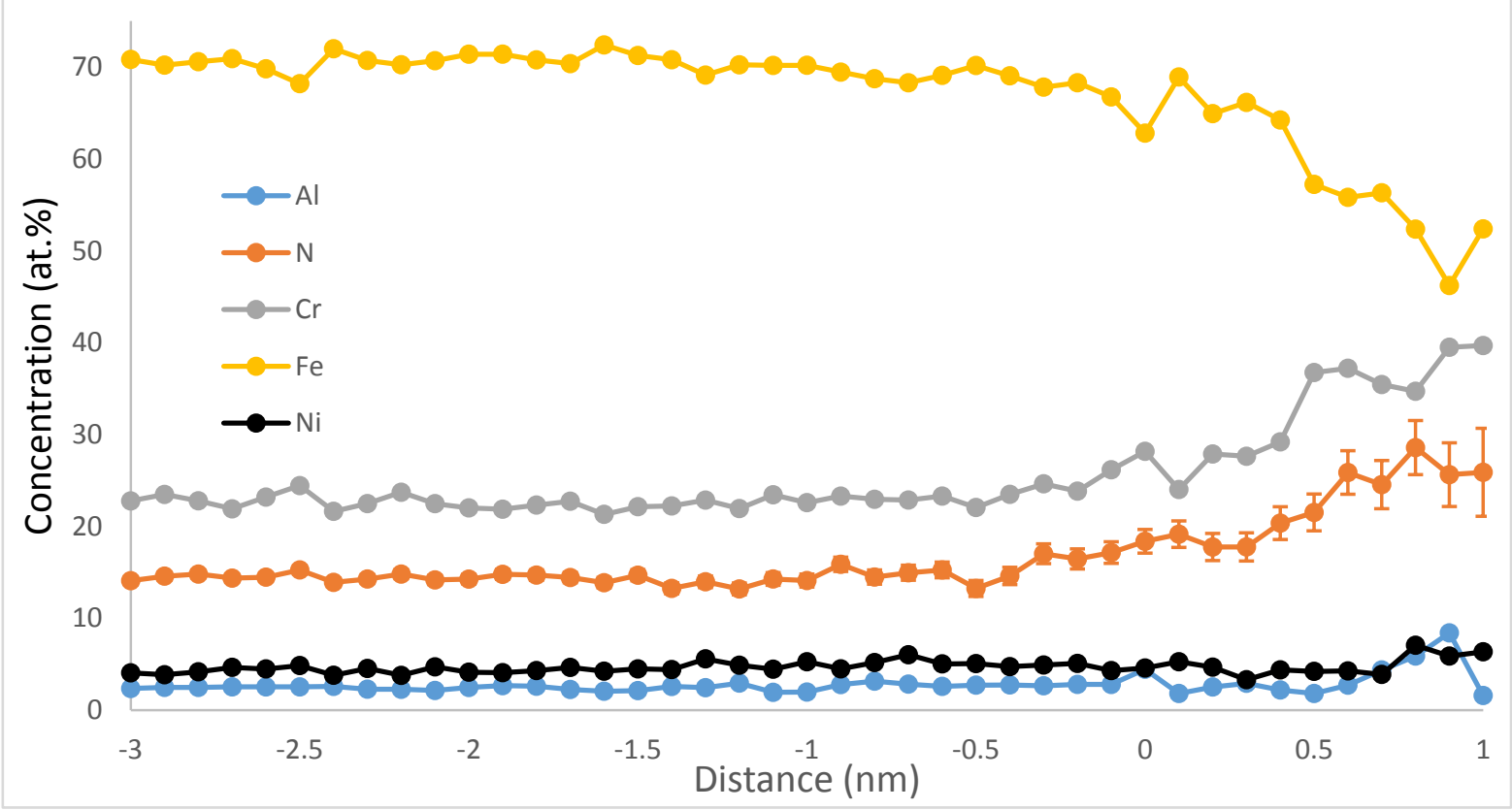

Fig. 3 (a) Projected 3D nitrogen map of the weak-contrast nitrided delta ferrite grain. (b) Proximity diagram of 18 at. $\% \mathrm{~N}$ isoconcentration surfaces (normalized without $\mathrm{N}$ ). (18 at.\% is an arbitrary value used to define the interfaces ( $0 \mathrm{~nm}$ on the $\mathrm{x}$-axis) between the nitrogen-rich clusters and the matrix. The shape of the proximity diagram is independent of the chosen value.) 

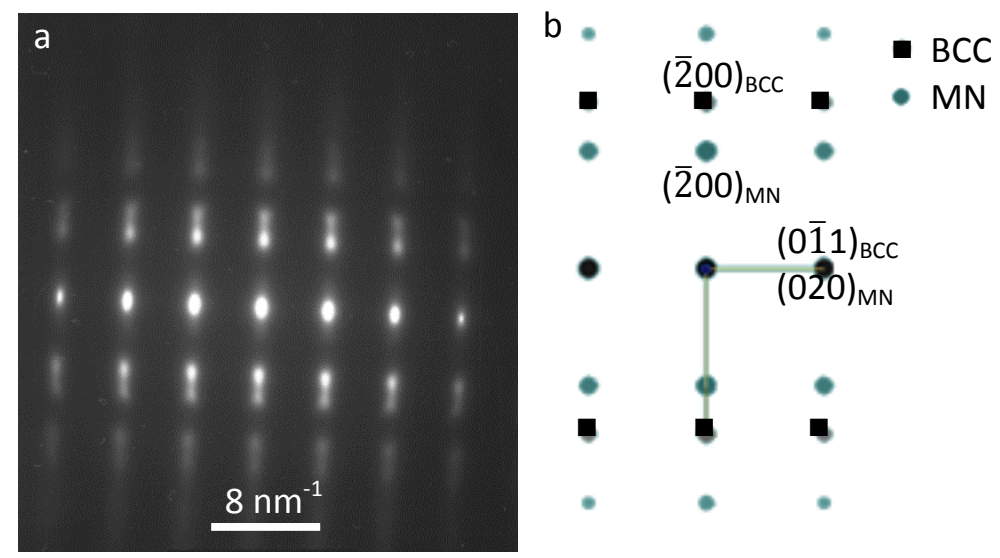

Fig. 4 (a) Diffraction pattern acquired from a $\langle 011\rangle_{\text {BCC }}$ zone axis of a nitrided weak-contrast delta ferrite grain. (b) Simulation of the BCC ferrite and the rocksalt-structured nitride obeying the Bain orientation relation. 


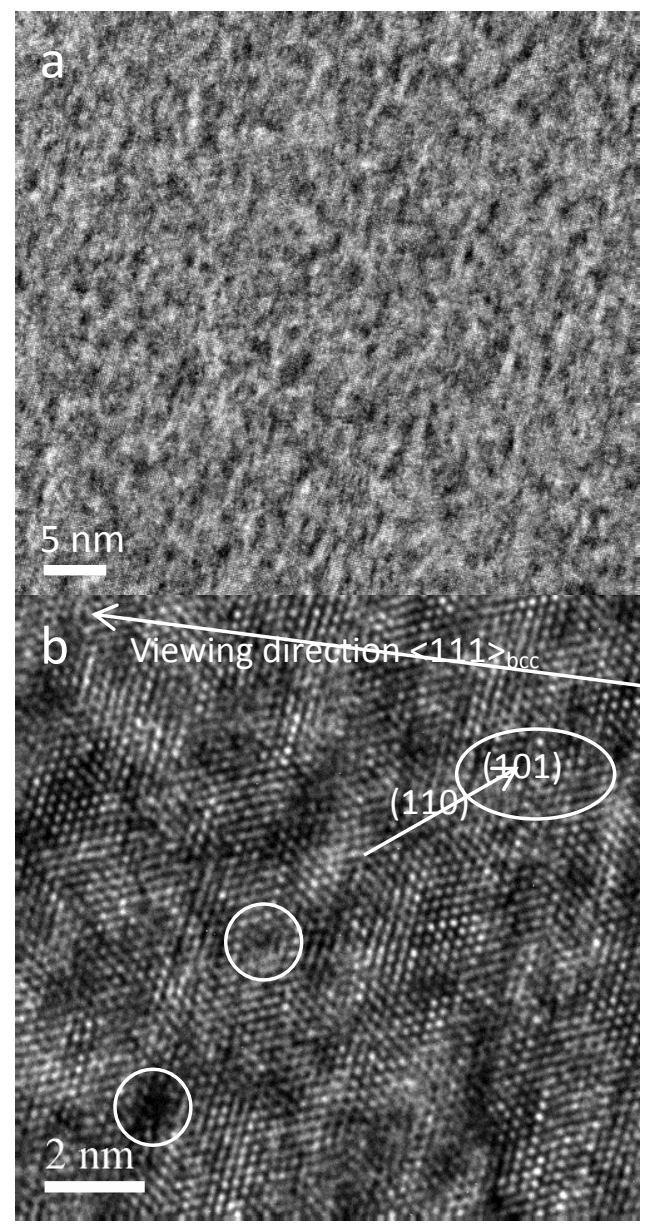

Fig. 5 HRTEM images acquired from nitrided weak-contrast ferrite grains. Highly disturbed (dark) regions are circled in Fig. 5b. 


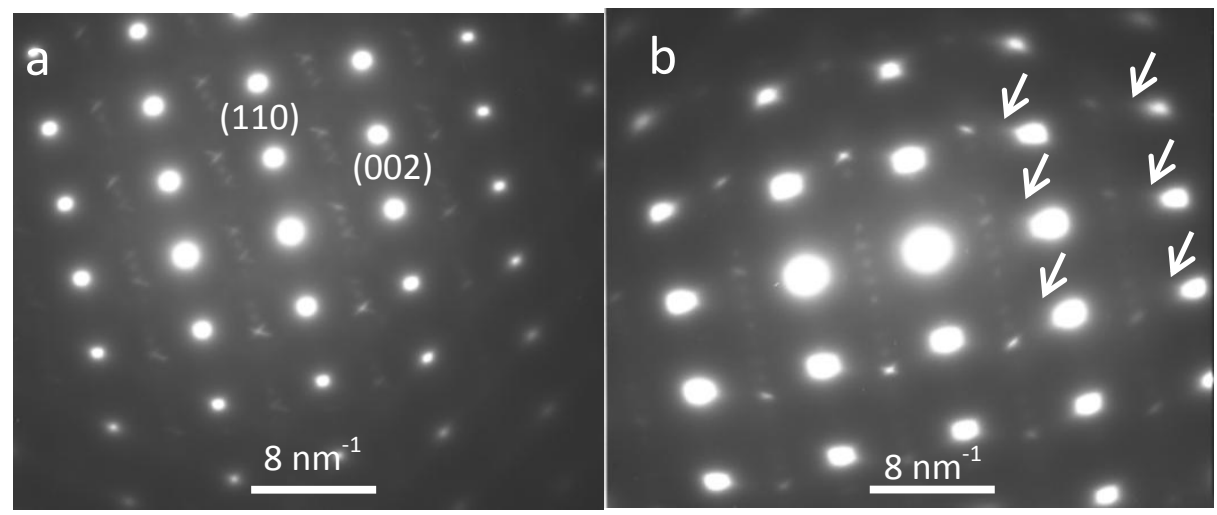

Fig. 6 Diffraction patterns acquired from the arrowed ferrite grain shown in Fig. 1a. (a) is from the lower portion of the grain (the original structure) and (b) is from the top, weak-contrast region. Signs of early-stage streaks are arrowed in (b). 

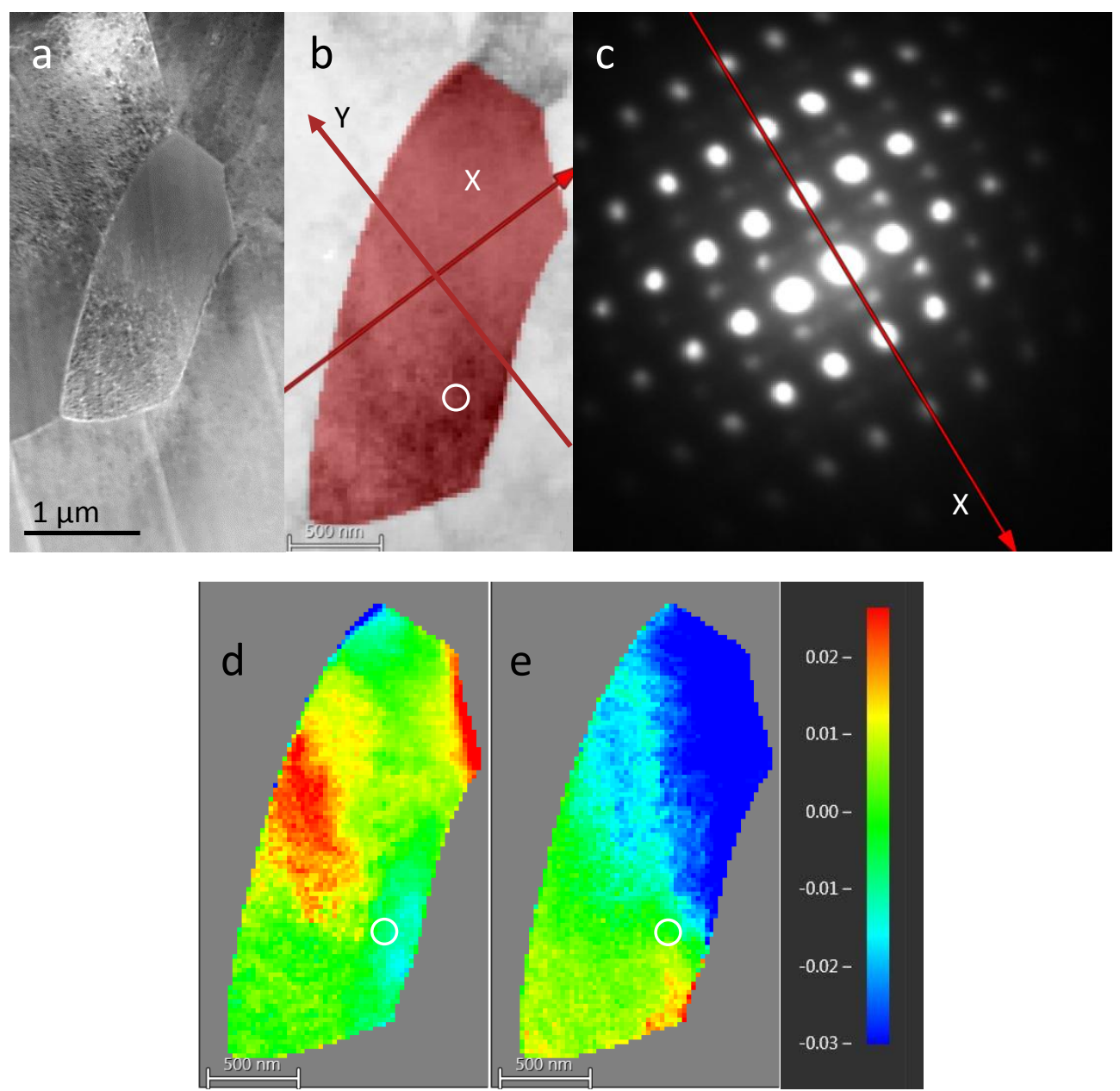

Fig. 7 Strain anlysis of the arrowed delta ferrite grain in Fig. 1a. (a) STEM image and (b) virtual brightfield image. The grain in red is where the strain analysis was acquired. The arrows indicate the $x$ and $y$ directions of the strain analysis in real space. (c) Reference diffraction pattern showing the $x$ direction $\left([001]_{\mathrm{BCC}}\right)$ of strain analysis in reciprocal space. (d) and (e) are strain maps along the $x$ and $y$ directions, respectively. The circles in (b), (d), and (e) indicate where the reference diffraction pattern was acquired. 

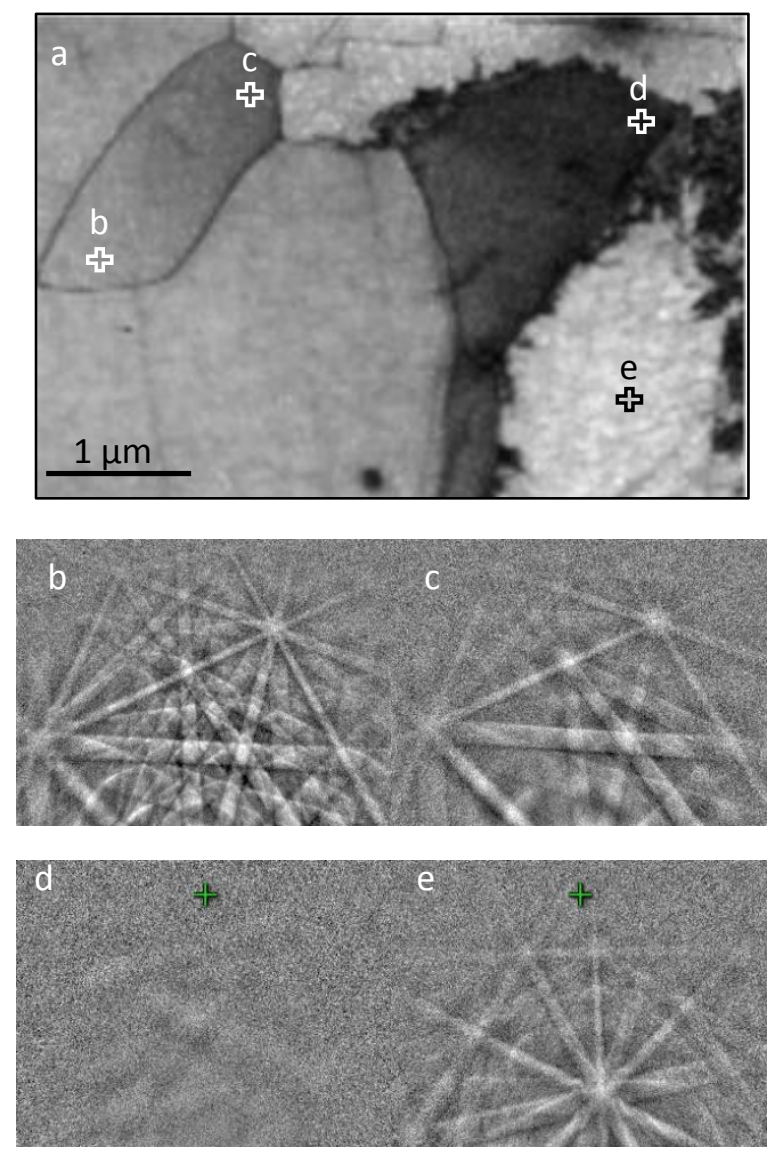

Fig. 8 (a) Band contrast map acquired by TKD. The original alloy surface is $\approx 8 \mu \mathrm{m}$ to the right. (b)-(e) Kikuchi patterns from corresponding positions labelled in (a). (b) and (c) are from the partially nitrided delta ferrite grain. (d) is from a weak-contrast nitride delta ferrite. (e) is from an austenite grain at a similar depth as the weak-contrast delta ferrite grain d. The Kikuchi pattern from the nitrided ferrite is completely smeared out. 


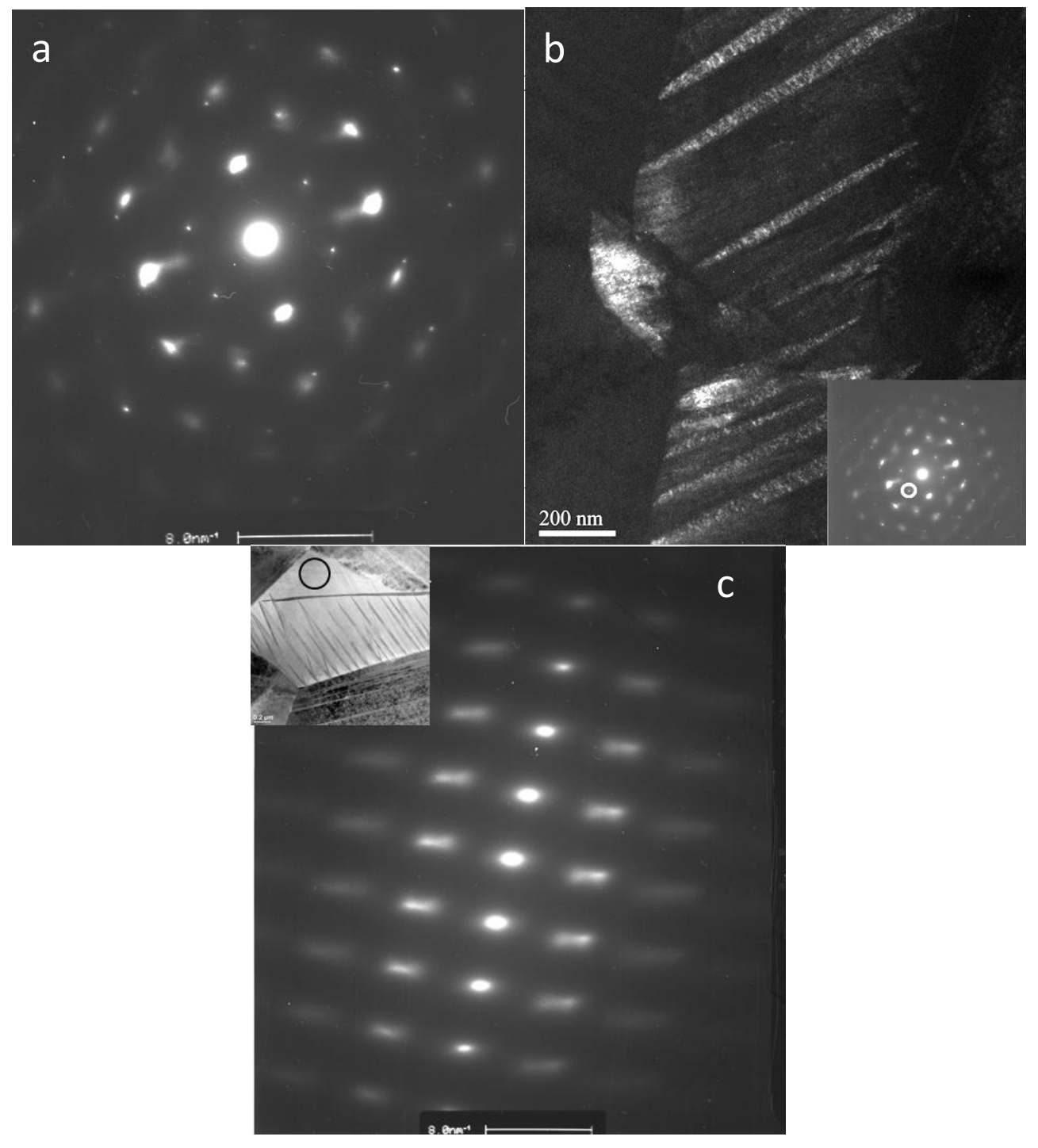

Fig. 9 (a) Diffraction pattern acquired from plate-containing nitrided delta ferrite grain along a $\langle 011\rangle_{\text {BCC }}$ zone axis. (b) Dark-field image from the nitride reflection circled in the inset. (c) Diffraction pattern acquired from a plate-free region in a plate-containing nitrided delta-ferrite. The inset shows the circled region where the diffraction pattern was acquired. 

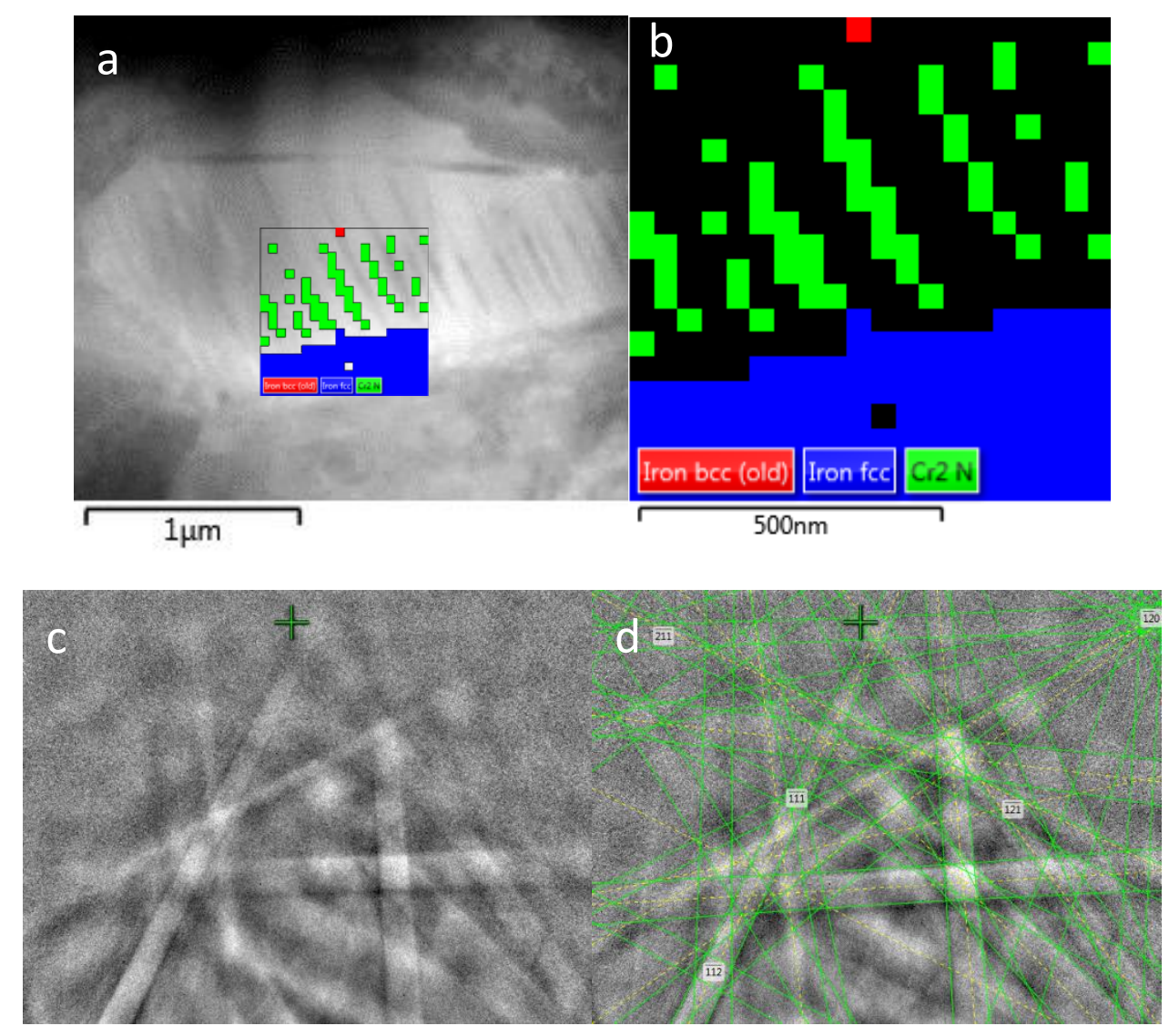

Fig. 10 TKD data acquired from a plate-containing delta ferrite grain. (a) Forward-scattering image with the overlay of the phase map (notice that drift occurred during the acquisition), (b) phase map. (c) Kikuchi pattern acquired from one of the nitride needles in (a). (d) Simulated solution $\left(\mathrm{Cr}_{2} \mathrm{~N}\right)$ for the pattern in (c). 
Nitrided delta ferrite grains in 17-7 PH stainless steel
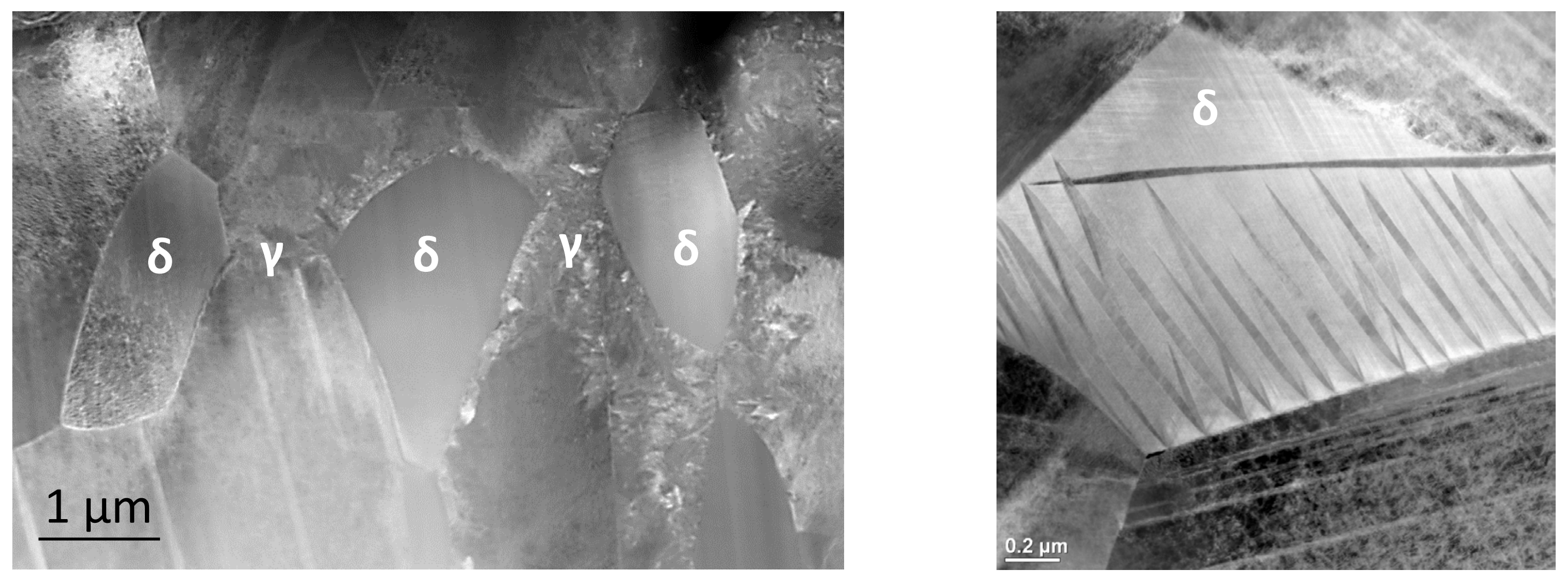